\title{
Biologia populacional de Astyanax altiparanae Garutti \& Britski (Teleostei, Characidae) do médio Rio Paranapanema, Paraná, Brasil
}

\author{
Mário Luís Orsi ${ }^{1}$, Edmir Daniel Carvalho ${ }^{2}$ \& Fausto Foresti ${ }^{2}$ \\ ${ }^{1}$ Departamento de Biologia Animal e Vegetal, Universidade Estadual de Londrina. Caixa Postal 6001, 86051-990 Londrina, \\ Paraná, Brasil. E-mail: orsi@uel.br \\ 2 Departamento de Morfologia, Universidade Estadual Paulista. Caixa Postal 510, Botucatu 18618-000, São Paulo, Brasil.
}

\begin{abstract}
Population biology of Astyanax altiparanae Garutti \& Britski (Teleostei, Characidae) of the medium river Paranapanema, Paraná, Brasil. This study was carried out with the following objective: determine the Astyanax altiparanae population structure. Four localities in the Paranapanema river basin were chosen (low Tibagi river) with distinct environmental characteristics. Sampling was carried out monthly from January 1997 to February 1998. A total of 1553 individuals were captured with constancy in all the river extensions, with greatest abundance in the Congonhas river (76\%). There was variation among the river extensions in the development phase, length class and spatial distribution of the captured specimens, showing that the species has a differentiated population structure although with similar growth. Therefore, the results suggested that the species has a great adaptive capacity to exploit and using differentiated strategies in terms of population structure. This showed that the species has a strong tendency to $r$ strategic behavior. It showed, however, preference for developing all its biological cycle at the Congonhas river first extension. This was probably due to environmental conditions favorable to the maintenance of the specie.
\end{abstract}

KEY WORDS. Ecology, fish, Tibagi.

RESUMO. O objetivo desse trabalho foi a determinação da estrutura populacional da espécie. Foram escolhidos quatro locais de amostragem com características ambientais distintas na bacia do rio Tibagi. As amostragens foram realizadas mensalmente no período de janeiro de 1997 a fevereiro de 1998. Um total de 1553 indivíduos foram capturados, apresentando constância em todos os trechos, com as maiores abundâncias nos trechos do rio Congonhas (76 \%).Variações ocorreram entre os trechos por fase de desenvolvimento e classes de comprimento e na distribuição espacial, demonstrando que a espécie apresenta estrutura populacional diferenciada. A espécie apresentou grande capacidade adaptativa exploratória, utilizando estratégias diferenciadas na estrutura da população.A espécie apresentou uma forte tendência ao comportamento $r$ estrategista. $O$ melhor desenvolvimento foi identificado em Congonhas I, talvez devido a existência de condições ambientais favoráveis a manutenção da espécie.

PALAVRAS CHAVE. Ecologia, peixes, Tibagi.

De acordo com WiNEMILLER (1989), o conhecimento da bionomia de uma população animal é um dos grandes objetivos da biologia atual, principalmente quando tais estudos são direcionados aos peixes teleósteos, que dentre os vertebrados, apresentam uma grande variabilidade de estratégias e táticas de sobrevivência.

Southwood (1988) e MANn et al. (1990) apresentam a hipótese de quanto é forte a relação entre as estratégias de sobrevivência das espécies com as características dos seus habitats, e ainda ressaltam que existe um sistema de seleção natural destas estratégias. Porém, para se ter idéia desse mecanismo, observam que é necessário um amplo conhecimento da biologia das espécies envolvidas. E isto significa um desafio à compreensão de todos os processos envolvidos nestas estratégias.

Neste contexto, Odum (1988) demonstrou que elementos da biologia populacional oferecem componentes que podem auxiliar e estabelecer os padrões de estratégia de sobrevivência das espécies. Entretanto, variações nos elementos de dada estratégia do ciclo vital realmente ocorrem e podem refletir a plasticidade da espécie, em relação ao seu ajuste às condições ambientais. Estas variações caracterizam-se como padrões adaptativos que se estabelecem em resposta a pressões ambientais de cada local e são definidas como táticas muito elaboradas. Além disso, WotTon (1998), considera que táticas distin- 
tas caracterizam respostas às flutuações ambientais, permitindo a manutenção de várias populações da mesma espécie em locais diferenciados.

Winemiller \& TAPHORN (1989), concluíram que as estratégias de vida evoluem como uma resposta à seleção natural e não representam artifícios fenotípicos correlacionados com outras características do organismo. Se existe um padrão seletivo apropriado, membros de táxons muito divergentes podem mostrar convergência em relação a suas estratégias de sobrevivência, e ainda mais, populações da mesma espécie podem apresentar divergência em suas estratégias no mesmo habitat.

Nos peixes Characiformes, as variações nas estratégias de vida estão presentes de forma muito evidente, tanto que este grupo exibe uma divergência fenotípica adaptativa tão grande que não se iguala a nenhuma outra ordem animal (FINK \& FinK 1981). Esse fato foi corroborado nos estudos sobre as estratégias reprodutivas dos Characidae das bacias hidrográficas brasileiras (VAzzoler \& Menezes 1992).

Vários autores, dentre eles Nikolsky (1969), Wellcome (1995), Garutti (1989), Wotton (1998) e Lowe - Mcconell (1999), vem estudando o ciclo de vida de populações de peixes neotropicais em diversos habitats da América do Sul. Estes estudos enfocam principalmente aspectos da alimentação e da reprodução, em que se constata uma grande variedade de táticas reprodutivas e alimentares, aparecendo com relevância o grupo da subfamília Tetragonopterinae.

Especificamente, o gênero Astyanax BAIRD \& GIRARD 1854 é o mais comum e diversificado da família Characidae na área de abrangência da região neotropical. O gênero congrega aproximadamente uma centena de espécies e que são abundantes nas bacias hidrográficas brasileiras (GÉrr 1977, GARUTTI \& BRITSKI 2000).

A espécie ainda apresenta uma abundância e distribuição significativa na bacia hidrográfica do rio Paranapanema (ShibatTa et al. 2002, Orsi et al. 2002), o que provavelmente ressalta a importância dessa espécie para o sistema ecológico.

Destas considerações, surge a seguinte indagação: como tal espécie consegue colonizar distintos habitats? Assim, os estudos sobre a biologia populacional de A. altiparanae na bacia hidrográfica rio Paranapanema, poderão contribuir de certa forma para a elucidação desta questão sobre a sua estratégia de vida.

Sendo parte de uma investigação mais abrangente sobre a espécie, o objetivo geral deste trabalho foi verificar componentes da biologia populacional de Astyanax altiparanae, determinando a existência ou não de um padrão populacional de ocupação da espécie, usando como ferramenta e objetivo principal à estrutura da população, em termos ecológicos.

Para atingir tal objetivo, foi necessário determinar a partilha da bacia hidrográfica em trechos e realizar a análise de modo comparativo. Dessa forma, foi estabelecido o objetivo específico que é determinar a estrutura populacional, com as análises de proporção entre os sexos, estrutura em tamanho, o fator de condição relativo e distribuição espacial da espécie em possíveis locais de ocupação da mesma.

\section{MATERIAL E MÉTODOS}

Os estudos desenvolvidos com a espécie Astyanax altiparanae Garutti \& Britski, 2000 (Fig. 2), foram na região da bacia hidrográfica do médio rio Paranapanema, abrangendo a porção final do seu principal afluente, o rio Tibagi. Região essa, situada no norte do Estado do Paraná, inserida no terceiro Planalto Paranaense.

Foram escolhidos quatro trechos (Fig. 1), que apresentavam distintas características físicas e ambientais, sendo um trecho na calha principal do baixo rio Tibagi denominado Limoeiro $\left(23^{\circ} 35^{\prime} 56^{\prime \prime} \mathrm{S}\right.$ e $\left.50^{\circ} 59^{\prime} 58^{\prime \prime} \mathrm{W}\right)$, um trecho no ribeirão Três Bocas $\left(23^{\circ} 37^{\prime} 39^{\prime \prime} \mathrm{S}\right.$ e $\left.51^{\circ} 04^{\prime} 44^{\prime \prime} \mathrm{W}\right)$ e dois outros trechos, compreendendo um subafluente de médio porte, o rio Congonhas e deste modo denominados os trechos como Congonhas I $\left(23^{\circ} 20^{\prime} 45^{\prime \prime} \mathrm{S}\right.$ e $\left.50^{\circ} 56^{\prime} 28^{\prime \prime} \mathrm{W}\right)$ e Congonhas II $\left(22^{\circ} 58^{\prime} 45^{\prime \prime} \mathrm{S}\right.$ e $\left.50^{\circ} 59^{\prime} 08^{\prime \prime} \mathrm{W}\right)$, compreendendo respectivamente, a porção média e final do rio e II, (Fig. 1).

Para a avaliação dos quatro trechos selecionados foram considerados os fatores físicos e químicos da água, como oxigênio dissolvido e transparência da água, e considerado a média mensal dos valores. A temperatura não foi contemplada por ter apresentado mínimas variações entre trechos e período de estudo. Quanto a situação ambiental da área foram observados a presença de vegetação marginal, conservação do solo ao redor, tipos de cultivos agrícolas e ação antropogênica presentes em cada região dos trechos.

As amostragens das populações de A. altiparanae foram mensais, sendo utilizadas duas seqüências de redes de espera, em ordem crescente, com malhas de 2, 3, 4, 5, e 6 cm entre nós opostos, com altura de 0,8 até $4,2 \mathrm{~m}$, perfazendo um total de $450 \mathrm{~m}^{2}$ de área de rede. Estas redes foram colocadas por dez horas, próximas às margens, no sentido perpendicular e em meia lua, em locais com profundidade mínima de 0,50 até $4,50 \mathrm{~m}$. Totalizando 56 coletas no período de janeiro de 1997 a fevereiro de 1998.

Foi empregado também o uso de tarrafas, peneiras e puçás, com um total de $8 \mathrm{~m}^{2}$ de área, para a captura de espécimes de pequeno porte. Este tipo de coleta, dependendo das condições do ambiente, seguiram dois procedimentos: 1) junto as macrófitas aquáticas e 2) próximas à margem, quando a vegetação marginal era ausente. Para estas coletas foram estabelecidos, o período de uma hora com lances sucessivos, numa extensão de aproximadamente $100 \mathrm{~m}$.

Foram obtidas observações complementares de visualização direta (observação a partir das margens), conforme a técnica preconizada por SABINO (1999) e RínCón (1999), utilizando-se também visualizações de barco ancorado. $\mathrm{O}$ intuito destas observações foi caracterizar de forma geral o comportamento da espécie, auxiliando com informações complementares a execução dos objetivos desse trabalho.

Para a verificação da distribuição dos peixes na coluna de água (em vertical) foram determinadas as posições em que

Revista Brasileira de Zoologia 21 (2): 207-218, junho 2004 


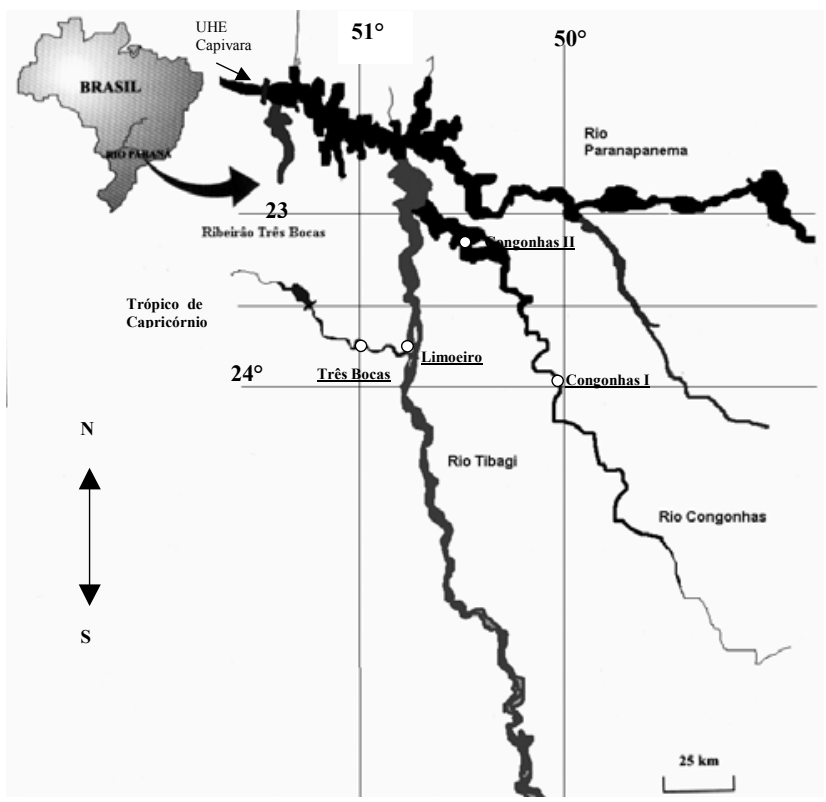

Figura 1. Mapa da região da bacia hidrográfica do baixo rio Tibagi e os respectivos, trechos de coleta (Limoeiro, Três Bocas, Congonhas I e Congonhas II).

os espécimes eram capturados na rede de espera, isto é, na porção superior (até 0,50 m da superfície), média (de 0,50 até $2 \mathrm{~m}$ ) e inferior (de 2 a $4 \mathrm{~m}$ de profundidade), e também a distância em que o peixe era capturado na rede até a margem (em perpendicular), denominado como distância curta (até $5 \mathrm{~m}$ da margem), média (de 5 a $10 \mathrm{~m}$ ) e longa (até o final das redes).

Ainda quanto a distribuição espacial dos espécimes, foram verificadas e quantificadas, em proporção (\%) de ocupação, a posição dos indivíduos capturados na coluna de água (posição vertical) e a sua distância (posição horizontal - perpendicular) em relação à margem. Estes dados foram então comparados graficamente entre os trechos, quanto à existência ou não de padrões de distribuição e utilizando-se do teste do $\chi^{2}$ na comparação.

Os exemplares de $A$. altiparanae tiveram sua biometria realizada, em relação ao comprimento total dos exemplares (Lt) em centímetros e o peso total dos exemplares (Wt) em gramas. Em seguida os animais eram eviscerados e logo após, retiradas as gônadas para determinação do sexo de cada indivíduo.

Nos quatro trechos amostrados foi verificada a freqüência de ocorrência mensal e total nas capturas, a proporção total entre os sexos, a distribuição de freqüência em classes de comprimento total, tamanho máximo e mínimo da espécie, o fator de condição relativo (bem estar da espécie - Kn) total nos trechos e mensal, a distribuição espacial dos indivíduos e atributos comportamentais.

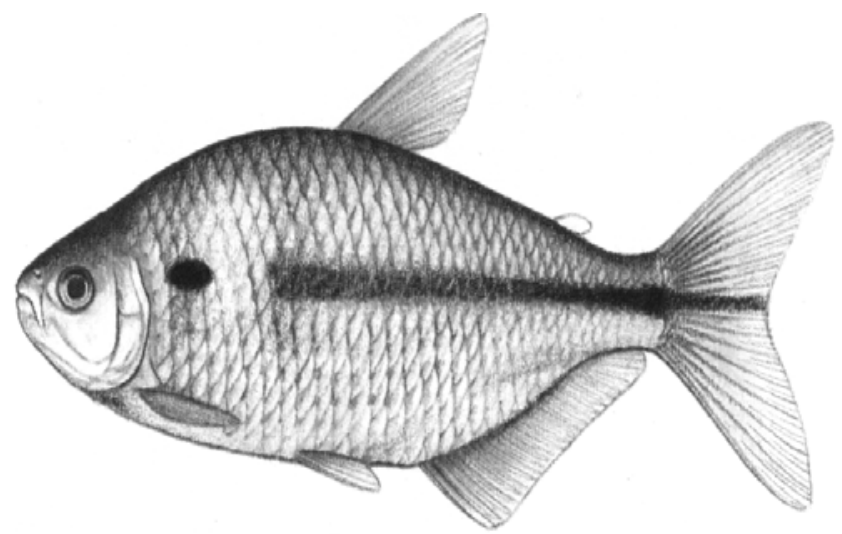

Figura 2. Ilustração de exemplar de Astyanax altiparanae da bacia hidrográfica do rio Tibagi, Paraná. Ilustração de Oscar Akio Shibatta.

Segundo Eckmann (1984) o fator de condição relativo (Kn) é um dos parâmetros utilizados para uma avaliação do bem estar geral da espécie. Assim, este parâmetro foi estimado em cada trecho, sendo obtido empiricamente pelo quociente entre o peso total observado (Wt) do espécime e o peso teoricamente inferido (Wesp), utilizando-se da expressão matemática da relação peso/comprimento, já aplicada para peixes (SANTOS 1978) para um dado comprimento, independentemente do sexo dos espécimes (EcKMann 1984).

Calculados os valores de Kn de todos os espécimes $(\mathrm{Kn}=$ Wt / Wesp.), estimaram-se as médias correspondentes aos respectivos trechos, sendo estes valores médios, comparados estatisticamente ao padrão $\mathrm{Kn}=1,0$, utilizando-se do teste " $\mathrm{t}$ " de Student $(\alpha=0,05)$. Além disso, a análise de variância, complementada pelo teste de Tukey para os agrupamentos das médias foi aplicada nestes valores médios de Kn.

Os dados da abundância numérica da espécie em cada trecho foram transformados em Captura por Unidade de Esforço (CPUE), que estima a abundância relativa em número de indivíduos por área e esforço, conforme método já utilizado por Agostinho et. al. (1997).

As médias mensais dos valores de CPUEn (em número) de cada trecho foram comparadas utilizando-se da análise de variância ANOVA - fator único e comparadas às médias agrupadas pelo teste de Tukey $(\mathrm{p}<0,05)$ para comparação de efetivas diferenças nas populações entre os trechos. A Análise mensal não foi inserida no trabalho por torna-lo muito extenso e não apresentar diferenças plausíveis de comparação.

Para podermos verificar a distribuição de freqüências de classes de comprimento total, foram estabelecidas oito classes de comprimento total (Lt) realizado pelo método de Sturges (SoKal \& Rohlf 1981). Verificamos no total de indivíduos capturados por trecho, o comprimento total (Ltm) máximo, comprimento total (Lt) médio, peso total (Wt), com o intuito também de verificar variações entre os trechos. 
Os sexos dos exemplares foram determinados macroscopicamente, sendo que a freqüência total entre os sexos da espécie foi estabelecida para cada trecho. Para verificar a existência de diferenças estatisticamente significativas foi realizado o teste $\chi^{2}$ em cada trecho estudado.

A análise da proporção de jovens e adultos nos quatro trechos de coleta foi estabelecida de acordo com o porte dos espécimes e o estado de desenvolvimento gonadal, seguindo os preceitos de Vazzoler (1996) para análise macroscópica das gônadas. Para a verificação de diferenças estatisticamente significativas entre a proporção total de jovens e adultos de cada trecho, foi aplicado o teste $\chi^{2}$.

Os peixes foram identificados pelo Dr. Oscar Akio Shibatta e os exemplares foram depositados na coleção ictiológica do Museu de Zoologia da Universidade Estadual de Londrina.

\section{RESULTADOS}

Somente os dados abióticos referentes a oxigênio dissolvido e transparência da água, apresentaram-se diferenciados entre os pontos estudados, denotando que as características de cada ambiente escolhido não foram idênticas. Os valores verificados de oxigênio dissolvido (OD), apresentaram diferenças estatisticamente significativas com o emprego da análise de variância. Com as médias mensais variando de 5,7 mg/l (menor valor) em Congonhas II a 9,15 mg/l (maior valor) em Congonhas I. $\mathrm{Na}$ análise estatística verificou-se que a média geral foi muito diferente (ANOVA, $F=88,81$ e $p<0,0001$ ). No teste de comparação múltipla de Tukey para as médias agrupadas, não foi verificada diferença estatística significativa para os trechos de Limoeiro e Três Bocas e Limoeiro com Congonhas I, porém ocorrendo no trecho de Congonhas II uma tendência de valores menores que os demais, apresentando um decréscimo pronunciado de setembro a fevereiro.

Os valores médios mensais de transparência da água, também foram diferenciados entre os trechos (ANOVA, $\mathrm{F}=25,69 \mathrm{e}$ $\mathrm{p}<0,0001)$ e quando foi utilizado o teste de comparação múltipla (Teste de Tukey), observou-se que nos trechos de Limoeiro e Três Bocas e Três bocas com Congonhas I, as diferenças não foram significativas. Porém, o menor valor de transparência de água foi registrado no trecho Congonhas II $(0,35 \mathrm{~m})$ e o maior no trecho de Congonhas I (1,98 m), com acréscimo nos valores para o período de junho a setembro, para ambos os trechos, mas somente o trecho de Congonhas I apresentou valores acima de $0,70 \mathrm{~m}$ de transparência da água, em todo período de estudo. Destes resultados destaca-se os Trechos de Congonhas I e II, apresentando a melhor e pior condição dos fatores abióticos respectivamente.

Das 56 coletas realizadas, foram capturados 1553 exemplares de A. altiparanae, possibilitando demonstrar com a analise da captura que a espécie apresentou-se constante nos quatro trechos amostrados e em todas as coletas.

Os resultados agrupados do número absoluto de ocorrência da espécie nos quatro trechos e a respectiva transforma- ção em CPUEN e abundância relativa (\%), estão contidos na tabela I. Nota-se que do total capturado, os dois trechos do rio Congonhas (I com 38,2\% e II com 35,4\%), representam um total de $76,3 \%$ das capturas, contrastando com apenas $24,7 \%$ dos outros dois trechos juntos.

Tabela I. A captura por unidade de esforço (CPUEN), número absoluto de captura e abundância relativa de Astyanax altiparanae, para os quatro trechos no período estudado.

\begin{tabular}{lccc}
\hline Trecho & $\begin{array}{c}\text { Número absoluto } \\
\text { de capturas }\end{array}$ & $\begin{array}{c}\text { Abundância } \\
(\text { CPUEn/1000m² } \\
\text { aparato/dia) }\end{array}$ & $\begin{array}{c}\text { Abundância } \\
\text { relativa (\%) }\end{array}$ \\
\hline Limoeiro & 159 & 353,3 & 10,2 \\
Três Bocas & 252 & 560,0 & 16,2 \\
Congonhas I & 593 & 1317,7 & $\mathbf{3 8 , 2}$ \\
Congonhas II & 549 & 1220,0 & 35,4 \\
Total & 1553 & 3451,1 & 100,0 \\
\hline
\end{tabular}

Na figura 3 observou-se a maior semelhança na CPUEn entre os trechos Congonhas I e II. Porém, o trecho de Congonhas I apresentou valor muito elevado de captura no mês de fevereiro de 1998. Nos trechos de Limoeiro e Três Bocas, no mês de julho, a captura da espécie apresentou os menores valores dentre os quatro trechos. De modo geral a abundância da espécie nas capturas foi distinta na maioria dos meses de estudo.

A análise de variância da CPUEn média mensal para cada trecho denotou diferenças significativas. Quando comparadas as médias agrupadas da CPUEn, através do Teste de Tukey, verificou-se que as maiores diferenças ocorreram entre os trechos Limoeiro e Congonhas I, seguido de Limoeiro e Congonhas II.

A avaliação das proporções totais entre jovens e adultos indicou uma predominância de adultos em todos os trechos (Tab. II). Cabe ressaltar que no trecho de Congonhas I houve a captura de maior número de jovens, contudo, constatou-se sempre o predomínio de indivíduos adultos, sendo que no trecho de Limoeiro não foi capturado nenhum indivíduo jovem.

Tabela II. Proporção (\%) de jovens e adultos dos quatro trechos estudados, com o respectivo teste do (2 dos exemplares analisados.

\begin{tabular}{lccc}
\hline \multirow{2}{*}{ Trechos } & \multicolumn{2}{c}{ Fase de desenvolvimento } & \multirow{2}{*}{ Teste $\chi^{2}$} \\
\cline { 2 - 3 } & Jovens & Adultos & \\
\hline Limoeiro & 0 & 100,0 & 100,0 \\
Três Bocas & 19,0 & 81,0 & 38,32 \\
Congonhas I & 24,3 & 75,7 & 26,48 \\
Congonhas II & 33,1 & 66,9 & 11,49 \\
\hline
\end{tabular}




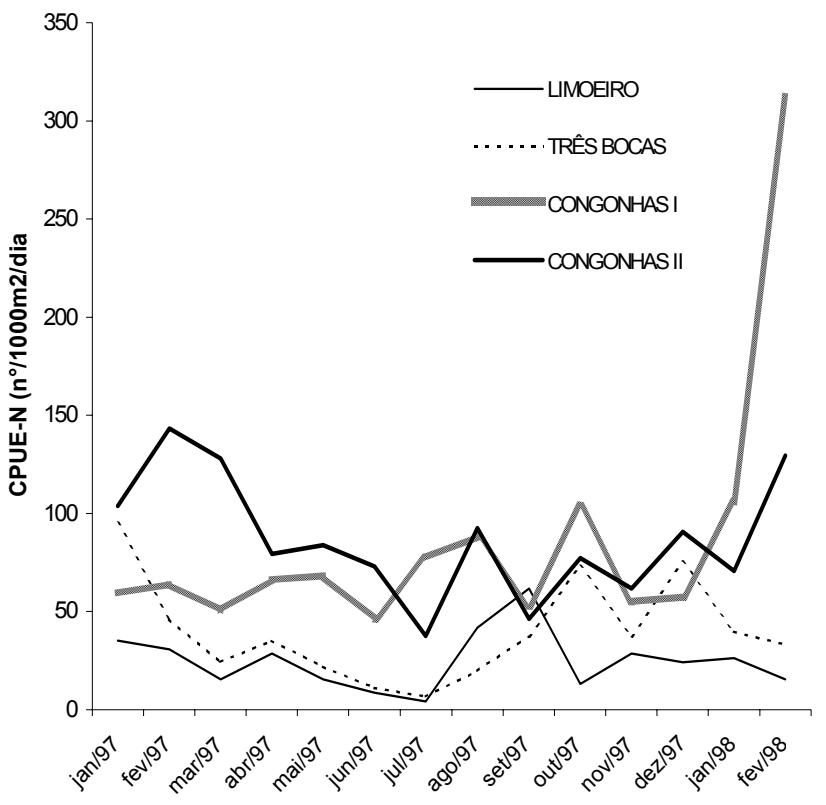

Meses de estudo

Figura 3. Abundância de captura (CPUEN) de Astyanax altiparanae nos quatro trechos amostrados durante o período de estudo.

Foram estabelecidas oito classes de comprimento a partir de 2,5 cm cada. Na figura 4 está representada a distribuição da freqüência relativa (\%) das classes de comprimento para a espécie nos quatro trechos.

Um fato que deve ser ressaltado foi que apenas o trecho Congonhas I, apresentou indivíduos compondo as oito classes de comprimento, enquanto que o trecho de Congonhas II apresentou o menor número de classes (cinco). A maior freqüência de indivíduos, na classe de comprimento $\mathrm{V}$, foi constatada em Limoeiro (50,9\%), enquanto nos trechos Três Bocas e Congonhas I, a maior freqüência foi a classe IV (38,5\% e 30,5\% respectivamente), e em Congonhas II a classe mais representada foi a III (32,3\%). Numa análise geral, constata-se que as classes IV e V foram as mais freqüentes em quase todos os trechos.

As composições de tamanho, máximo, mínimo e médio do comprimento total e peso total da espécie, quando avaliadas revelou que em todos os trechos essas variáveis biológicas foram diferentes (Tab. III). Os indivíduos do trecho de Congonhas I apresentaram os maiores valores totais de comprimento e peso, contrastando com os menores valores respectivos dos indivíduos para o trecho de Congonhas II. Já para o trecho de Limoeiro, foram observados os maiores valores médios dentre os trechos estudados.

Ao estabelecer a proporção entre os sexos, com os dados agrupados, verificou-se que o número de fêmeas (absoluto ou relativo) sempre foi maior (Tab. IV). Entretanto, apenas para os trechos Congonhas II e Limoeiro ficou evidente a existência de diferença estatística significativa entre os sexos, quando

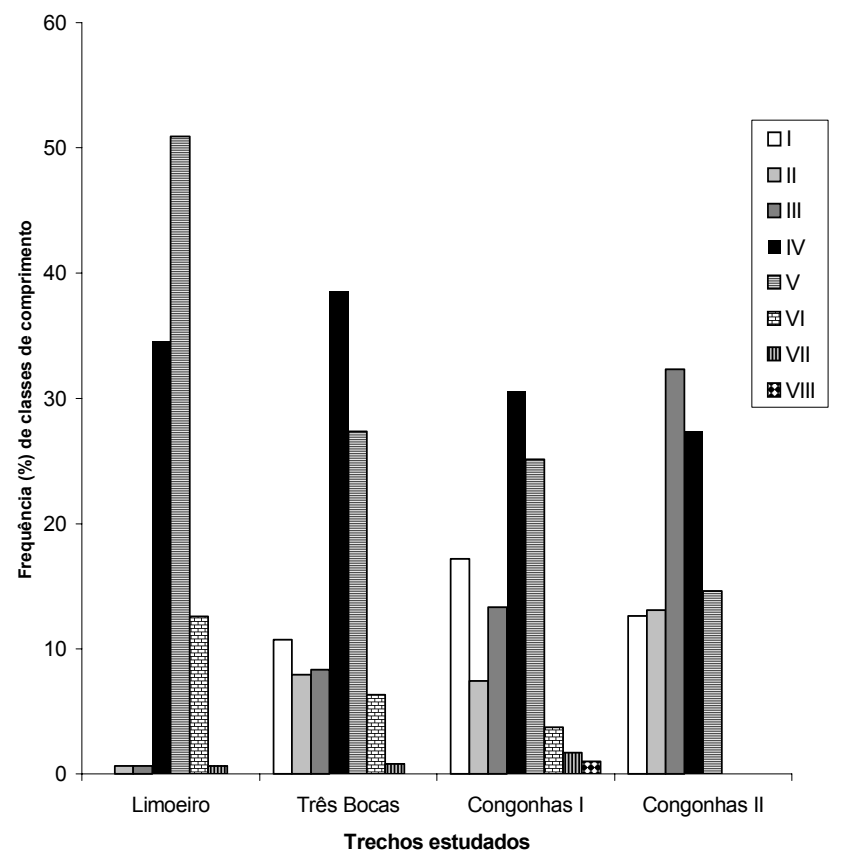

Figura 4. Freqüência relativa de classes de comprimento total, estabelecido a partir de $2,5 \mathrm{~cm}$, (machos e fêmeas agrupados) de Astyanax altiparanae, para os quatro trechos analisados, no período de estudo.

Tabela III. Composição em tamanho, comprimento total médio (Lt), peso total médio (Wt), e respectivos valores máximos e mínimos e desvio padrão dos espécimes de Astyanax altiparanae, dos quatro trechos analisados, durante o período de estudo.

\begin{tabular}{|c|c|c|c|c|c|c|c|c|}
\hline \multirow[t]{2}{*}{ Trechos } & \multicolumn{2}{|c|}{$\begin{array}{l}\text { Valores } \\
\text { máximos }\end{array}$} & \multicolumn{2}{|c|}{$\begin{array}{l}\text { Valores } \\
\text { mínimos }\end{array}$} & \multicolumn{2}{|c|}{$\begin{array}{l}\text { Valores } \\
\text { médios }\end{array}$} & \multicolumn{2}{|c|}{$\begin{array}{l}\text { Desvio } \\
\text { padrão }\end{array}$} \\
\hline & Lt & $\mathrm{Wt}$ & $\mathrm{Lt}$ & $\mathrm{Wt}$ & Lt & $\mathrm{Wt}$ & $\mathrm{Lt}$ & $\mathrm{Wt}$ \\
\hline 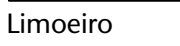 & 15,60 & 52,01 & 5,5 & 4,02 & 10,93 & 20,88 & 1,49 & 7,22 \\
\hline Três Boca & 16,10 & 68,32 & 1,7 & 0,29 & 8,42 & 14,01 & 3,25 & 10,24 \\
\hline Congonh & 18,90 & 82,35 & 0,5 & 0,27 & 8, &, 32 & 3,7 & 12,96 \\
\hline ongonhas II & 11,90 & 42,66 & 0,5 & 0,21 & 7,53 & 10,91 & 3,04 & 7,81 \\
\hline
\end{tabular}

Tabela IV. Proporção entre os sexos da espécie Astyanax altiparanae, entre os quatro trechos estudados e a aplicação do teste X2. * significativo para X2 $>3,84(p<0,05)$.

\begin{tabular}{|c|c|c|c|c|}
\hline \multirow{2}{*}{ Trechos } & \multirow{2}{*}{$\begin{array}{c}\text { Freqüência } \\
\text { absoluta }\end{array}$} & \multicolumn{2}{|c|}{ Testes do X2 } & \multirow{2}{*}{ Razão sexua } \\
\hline & & Machos & Fêmeas & \\
\hline Limoeiro & 53 & 106 & $11,69^{*}$ & $1: 2$ \\
\hline Três Bocas & 89 & 117 & 1,84 & 1: 1 \\
\hline Congonhas I & 190 & 254 & 2,07 & 1: 1 \\
\hline Congonhas II & 102 & 314 & $26,01^{*}$ & $1: 3$ \\
\hline
\end{tabular}

Revista Brasileira de Zoologia 21 (2): 207-218, junho 2004 
utilizado o teste do $\chi^{2}$. Rejeitando para os espécimes deste dois trechos a hipótese nula $\left(\mathrm{HO}, \chi^{2}>3,84\right)$, para $\mathrm{p}<0,05$. As maiores proporções de fêmeas constatadas nos trechos de Limoeiro e Congonhas II foram de duas e três fêmeas respectivamente para cada macho (Tab. V).

Tabela V. Valores médios do fator de condição relativo (Kn), com os respectivos intervalos de confiança (IC) e o teste de Tukey e "t" de Student, para espécie Astyanax altiparanae dos trechos analisados no período em estudo. $\left({ }^{*}\right)$ Significativamente diferente.

\begin{tabular}{lccccc}
\hline \multicolumn{1}{c}{ Trecho } & $\mathrm{N}$ & $\begin{array}{c}\mathrm{Kn} \\
\text { médio }\end{array}$ & $\begin{array}{c}\text { Intervalo de } \\
\text { Confiança }\end{array}$ & $\begin{array}{c}\text { Teste de } \\
\text { Tukey }\end{array}$ & $\begin{array}{c}\text { Teste "t" de } \\
\text { Student }\end{array}$ \\
\hline Limoeiro & 159 & 0,99 & 0,0012 & $\mathrm{p}<0,05^{*}$ & $\mathrm{p}>0,05$ \\
Três Bocas & 252 & 0,99 & 0,0813 & $\mathrm{p}<0,05^{*}$ & $\mathrm{p}>0,05$ \\
Congonhas I & 593 & 1,01 & 0,0681 & $\mathrm{p}<0,05^{*}$ & $\mathrm{p}>0,05$ \\
Congonhas II & 548 & 0,68 & 0,0945 & $\mathrm{p}<0,0001^{*}$ & $\mathrm{p}<0,05^{*}$ \\
\hline
\end{tabular}

$\mathrm{Na}$ análise da relação peso/comprimento, os seguintes coeficientes foram obtidos para a expressão matemática da curva teórica: $\phi=0,0159, \theta=3,0023$ e $\mathrm{R}^{2}=0,9818$. Na tabela $\mathrm{V}$ estão representados os valores médios do fator de condição relativo (Kn) de A. altiparanae para os trechos e os respectivos intervalos de confiança e resultados da análise estatística.

Aplicando-se o teste " $\mathrm{t}$ " de Student $(\mathrm{a}=0,05)$, constatou-se que Congonhas II apresentou diferença estatisticamente significativa nesse parâmetro biótico e que os demais trechos apresentaram valores muito próximos ao valor de base dessa análise $(\mathrm{Kn}=1,0)$.

A análise de variância (ANOVA - fator único) e o teste de comparação de Tukey das médias agrupadas de Kn ajudaram a demonstrar que os trechos foram estatisticamente semelhantes $(\mathrm{F}=73,63$ e $\mathrm{p}<0,05)$, com exceção de Congonhas II, e denotaram a mesma tendência, acima descrita, apresentando Congonhas II com resultados bem discrepantes dos demais. $\mathrm{O}$ mesmo padrão foi verificado para os resultados de Kn mensal, com evidente decréscimo de valores nos meses de abril até agosto (período mais seco), principalmente para o trecho de Congonhas II e Três Bocas (Fig. 5).

No total de espécimes analisados quanto à distribuição espacial, foi constatado uma forte tendência de ocupação da espécie na porção superior e média da coluna de água (Fig. 6). Enquanto que no trecho de Limoeiro não foi encontrado nenhum indivíduo na porção inferior da coluna de água. Além disso, o teste do $\chi^{2}$ mostrou que para o trecho de Congonhas I, não foram constatadas diferenças estatisticamente significativas (para $\mathrm{p}>0,05$ e $\chi^{2}<3,84$ ) entre a ocupação da porção superior $(45,6 \%)$ e média $(47,5 \%)$.

A distribuição espacial dos espécimes quanto a distância de captura em relação à margem (Fig. 7), evidenciou que nos trechos Limoeiro $(61,1 \%)$ e Congonhas II $(68,2 \%)$, a espécie ocupou principalmente a distância próxima e média da mar-

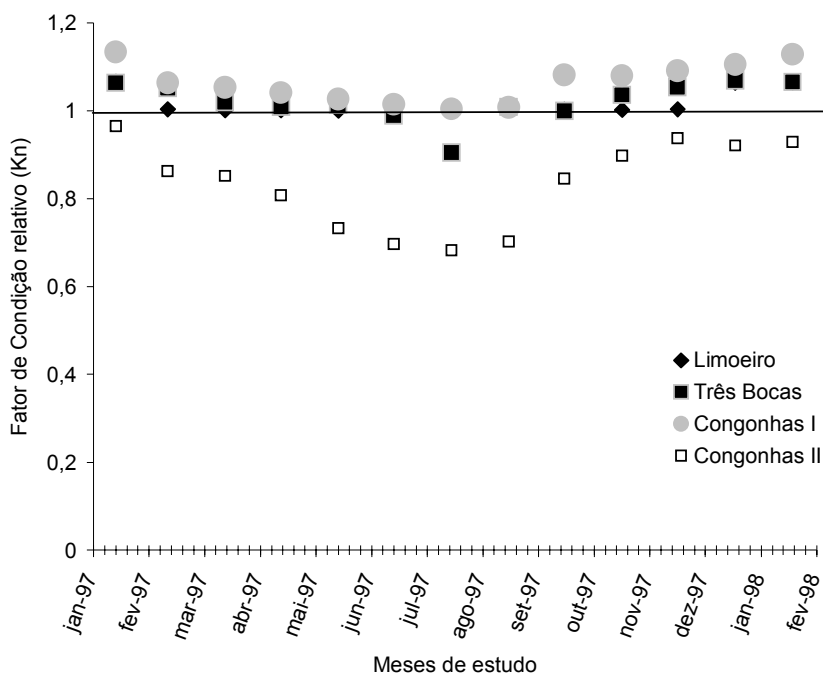

Figura 5. Variação dos valores do fator de condição relativo $(K n)$ mensal, comparativo ao valor padrão $(K n=1,0)$, e em relação ao peso total da espécie Astyanax altiparanae nos quatro trechos, durante o período de estudo.

gem. Por outro lado, nos trechos de Três Bocas $(66,3 \%)$ e Congonhas I $(43,0 \%)$, a preferência de ocupação evidenciada foi na distância média, apesar dos espécimes serem encontrados ocupando todas as áreas, isto é, de margem à margem nestes dois trechos.

O emprego da observação com a visualização direta (Figs 8-11) permitiu identificar um padrão de distribuição da espécie, como o agrupamento e o posicionamento espacial da espécie para os trechos. Porém, foram encontradas grandes limitações na aplicação da técnica, principalmente no período de maior pluviosidade (novembro a março), com a conseqüente diminuição da transparência da água e aumento da correnteza.

A espécie apresentou um padrão de distribuição agregado para três trechos, formando pequenos cardumes, com aproximadamente 50 indivíduos, sendo exceção o trecho de Limoeiro, onde se observou apenas agrupamentos pequenos, de no máximo 10 indivíduos. Já no trecho de Congonhas II ficou evidente encontrar vários cardumes, com o padrão comum de grupos, mas segregados por tamanhos diferentes (Figs 10-11).

Em Congonhas I, os cardumes com indivíduos de pequeno tamanho eram observados sempre na margem, junto a vegetação (macrófitas, raízes e galhadas submersas) e realizando movimentos curtos e rápidos com número grande de espécimes (acima de 40 indivíduos), ocorrendo principalmente nos meses mais secos (abril a agosto) (Fig. 10). Os grupos de peixes de maior tamanho ocorriam sempre em menor número de espécimes (aproximadamente 15), e realizavam movimentos rápidos e longos, indo da margem até a porção média do rio Congonhas e retornando novamente várias vezes, dando indi- 

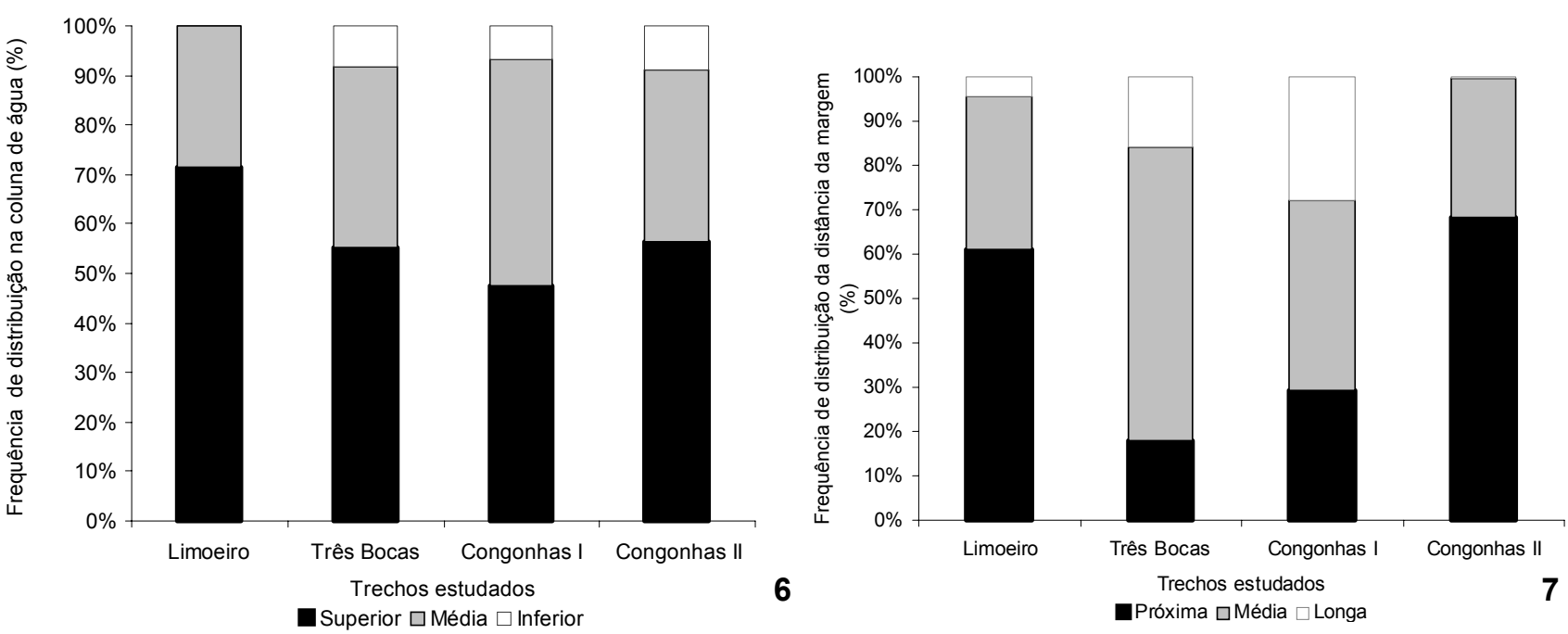

Figuras 6-7. Freqüência relativa (\%) da distribuição espacial na coluna de água (6) e quanto a distância de captura em relação a margem (7) dos espécimes de Astyanax altiparanae nos quatro trechos, durante o período de estudo.
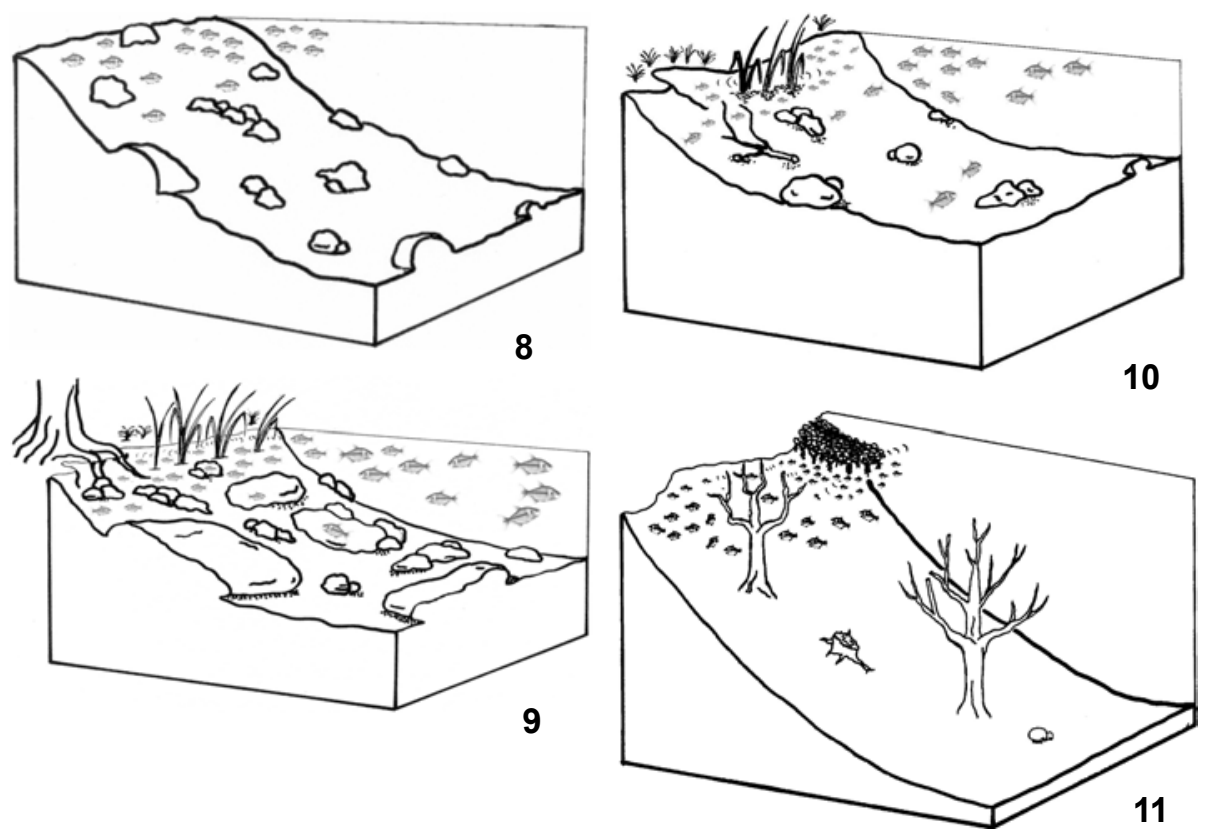

Figuras 8-11. Esquema ilustrativo das observações diretas realizadas durante o período de estudo, demonstrando o posicionamento e forma de agrupamentos de Astyanax altiparanae nos trechos de: (8) Limoeiro; (9) Três Bocas; (10) Congonhas I; (11) Congonhas II.

cações de ser um comportamento alimentar. Um padrão semelhante também foi observado nos demais trechos, porém no trecho de Limoeiro, apenas grupos de indivíduos adultos pouco dispersados foram visualizados (Figs 10-11).

A maioria das observações corroborou aos resultados obtidos na análise de distribuição espacial, evidenciando preferência da espécie à áreas marginais e superfície dos rios, mas com tendência a ambientes de correnteza pouco acentuada.

Na grande maioria das observações, a espécie ocupava habitats do tipo "Pool" (Bisson et al. 1988), como poços próximos a corredeiras e perto das margens, a exceção de Congonhas II, onde as características físicas foram totalmente diferenciadas (reservatório) e a espécie ocupou espaços com a presença de bancos de macrófitas, e próximo a galhadas de árvores submersas. 


\section{DISCUSSÃO}

A constância de captura verificada nos permite dizer que A. altiparanae está amplamente distribuída na região do médio rio Paranapanema (Baixo Rio Tibagi) e assim, caracterizada como uma espécie residente. LOWE-MCCONNELL (1999) afirma que as espécies constantes em todas as coletas fazem parte da comunidade aquática ali presente e, segundo definição de Mathews (1998), podemos considerar que $A$. altiparanae foi componente real da assembléia de peixes desses trechos.

A presença ou ausência de uma ou mais espécies em determinados ambientes não depende somente das condições específicas de um habitat particular, mas também da disponibilidade de outras áreas apropriadas para alimentação, reprodução e refúgios adjacentes a esse habitat (LowE-MCCONNELL 1999). Fato esse que deve ter interferido também na abundância e distribuição da espécie para os quatro trechos, que se mostraram diferentes nesses atributos.

Os resultados equivalentes sobre a constância dessa espécie na bacia do rio Paranapanema e rio Tibagi (BenNemann et al. 1995, Carvalho et al. 1998) mostram tanto uma ampla distribuição geográfica como a sua capacidade de ocupar diferentes habitats destes biótopos.

Para a abundância numérica da espécie, foi constatado que apesar de terem ocorrido diferenças entre os trechos, percebe-se que há uma tendência de dois padrões. O primeiro padrão foi verificado nos trechos de Limoeiro e Três Bocas, com freqüências mais baixas durante todo o período de estudo e uma rarefação nos meses de junho e julho, enquanto que no segundo padrão em Congonhas I e Congonhas II, a abundância foi mais elevada, principalmente nos meses chuvosos (janeiro e fevereiro).

Entretanto, três hipóteses poderiam explicar tais diferenças: 1) o efeito das técnicas de amostragens e 2) as diferenças nas características ambientais. Reforçando a última hipótese, SHibatTa (comum. pessoal) ressalta que essa espécie não é capturada em regiões com fortes correntezas da cabeceira da bacia do rio Tibagi. O mesmo fato foi constatado por BenNEMANn $e t$ al. (1995) е Sнiватта et al. (2002), que verificaram baixas freqüências dessa espécie em trechos de correnteza acentuada do Alto e Médio Rio Tibagi e ausência em porções de cabeceira de afluentes de pequena ordem. Uma terceira hipótese poderia estar associada a esses padrões de abundância, a presença ou ausência de refúgios, tais como macrófitas aquáticas, galhos e troncos submersos, nas áreas adjacentes. Como suporte desta hipótese foi constatado que no trecho de Limoeiro não há refúgios evidentes e a abundância foi menor que em Três Bocas que apresentou vários refúgios.

A abundância da espécie expressa pelo CPUEN mensal nos trechos, permitiu evidenciar (com exceção de Limoeiro), que os valores elevados de abundância da espécie coincidem com o período chuvoso (Janeiro e fevereiro de 1997 e de setembro 1997 a fevereiro de 1998), o que pode ser um indicativo em relação ao período de reprodução associado a condições favoráveis, como aporte de material alóctone e aumento de áreas de refúgio. Dessa forma, o conhecimento da abundância de espécies e dos fatores que podem estar correlacionados representam uma ferramenta importante para a ecologia de populações de peixes e o papel das mesmas no ecossistema (BEGON et al. 1988, WineMILLER 1996).

Araújo (1998) e Paller et al. (1996), descrevem que elevados valores de captura por unidade de esforço (CPUE) são freqüentemente encontrados em rios com alta riqueza de espécies e de boa qualidade de água, enquanto baixos valores de CPUES são comuns em sistemas fortemente degradados. Discordamos em parte dessa colocação, pois muitas vezes a abundância de peixes é peculiar do sistema analisado, demonstrando as características de um determinado ambiente em suportar uma população ou comunidade aquática. Em ambientes altamente impactados, como por exemplo, a represa de Barra Bonita na bacia do rio Tietê (São Paulo), foi constatado um maior rendimento pesqueiro e diversidade de peixes, em relação a represa de Jurumirim (bacia do rio Paranapanema) sendo, porém menos degradada (CARVALHo \& SiLVA 1999).

Ainda em relação a abundância e distribuição, RickLefs 2003, salienta que não devemos esquecer a capacidade que determinada população possui em ajustar-se a situação ambiental vigente, seja por questões fenotípicas, e ou, genotípicas inerentes à espécie. Um indicativo dessa situação à A. altiparanae foi evidenciada com a grande abundância da mesma no trecho de Congonhas II, considerada uma das regiões mais degradadas da bacia do rio Tibagi (Orsi et al. 2002).

A análise da distribuição de jovens e adultos entre os quatro trechos demonstrou que apenas em Limoeiro não ocorreram jovens, sendo a população em sua totalidade, composta de adultos. Nos demais trechos, a presença de ambas as fases de desenvolvimento, evidenciou o recrutamento de novos indivíduos nessas populações, principalmente em Congonhas I, corroborando as colocações de Benedito-Cecílio \& Agostinho 1997, e ainda demonstrando que esses habitats foram realmente favoráveis ao desenvolvimento da espécie.

Copp (1992) sugere que a estruturação de populações de peixes de água doce em determinados locais, coincide com o aparecimento de diferentes fases de desenvolvimento (ovos, larvas, jovens e adultos), podendo caracterizar a capacidade destas em ocupar de forma eficiente o ecossistema em questão.

No trecho de Limoeiro, a ausência de fases juvenis nos permite sugerir que esta não é uma área propícia para a reprodução da espécie, podendo representar apenas um trecho de alimentação ou trânsito, a qual os indivíduos adultos conseguem explorar. Talvez devido à presença de fatores limitantes como a forte correnteza e ausência de refúgios contra a predação. Ao contrário, Congonhas I aparentou ter as melhores condições ambientais para o recrutamento, como áreas de refúgio, reprodução e desenvolvimento, visto o número elevado de capturas de indivíduos em fase inicial de desenvolvi-

Revista Brasileira de Zoologia 21 (2): 207-218, junho 2004 
mento, e em seguida Congonhas II e Três Bocas também com condições razoáveis à permanência de jovens.

As diferenças encontradas na freqüência de distribuição em classes de comprimento podem ser relacionadas às características ambientais distintas dos trechos. Estas variações no padrão de tática de desenvolvimento da espécie relacionamse, tanto com os fatores abióticos de cada local, como à predação, à disponibilidade de alimento, à fecundidade e à mortalidade, agindo como pressão seletiva sobre a estrutura destas populações. Especificamente, em Congonhas II foi constatada apenas a presença de classes de menor comprimento, o que poderia ser um reflexo da predação sobre a estrutura populacional, uma vez que neste trecho verifica-se a presença de maior número de espécies piscívoras, entre os ambientes estudados (Shibatta et al. 2002, Orsi et al. 2002).

Lowe-McConNell (1999) relata que a predação pode interferir nos processos de manutenção e sobrevivência das espécies próximas a base da cadeia trófica, como é o caso dos lambaris. Este fato parece ter suporte na condição, de que a região do trecho Congonhas II oferece condições físicas semelhantes a de um reservatório, que possibilitam o aparecimento de um maior numero de espécies piscívoras de peixes (AgostiNHo \& Júlio JR. 1999).

Como já observado no estudo de Bennemann \& Shibatta (2002), em trecho muito próximo ao de Congonhas II (Bacia do rio Tibagi), cerca de cinco espécies piscívoras nativas, e principalmente a espécie introduzida Plagioscion squamosissimus (Heckel, 1840), utilizam A. altiparanae como uma de suas principais fontes de alimento. Os estudos de HAHN et al. (1997) corroboram a essa questão, verificando que $A$. altiparanae foi uma das espécies mais predadas por peixes piscívoros, na planície de inundação do rio Paraná.

A constatação da ocorrência de várias classes de comprimento nos trechos Três Bocas e Congonhas I pode significar a presença de grupos etários coexistindo, no espaço e no tempo, dando o indicativo de que esses ambientes apresentaram condições favoráveis ao desenvolvimento da mesma.

Nikolsky (1969) salienta que as espécies de peixes conseguem manter-se sob condições continuamente dinâmicas e que a estrutura em comprimento pode ser alterada dentro de limites típicos da espécie, e que essa flexibilidade de táticas representa um ajuste às mudanças do meio dentro das condições de sobrevivência.

Podemos ressaltar dessa forma, que a composição em classes de comprimento refletiu as condições ambientais presentes e pregressas, nas quais a população se desenvolveu, dando suporte para afirmar que $A$. altiparanae possui grande capacidade de ajuste a diversas situações ambientais.

Os valores máximos de comprimento e peso encontrados nos trechos de Congonhas I e Congonhas II nos permitiram demonstrar que no mesmo rio foi possível observar diferenças intraespecificas, que parecem estar diretamente relacionadas à variabilidade de habitats. GARUTTI (1989), estudando esta espécie em vários trechos e rios da região nordeste do Estado de São Paulo mostrou o ajuste das diferentes populações à variabilidade de habitats.

Por outro lado, os menores valores de comprimento e peso detectados no trecho de Congonhas II podem também ser uma conseqüência de alterações ambientais, ali presentes, devido ao efeito de represamento. Pois apesar deste ambiente oferecer extensas áreas de macrófitas e a ocorrência de uma estrutura populacional com condições razoáveis, outros fatores poderiam estar interferindo negativamente na espécie e traduzidos pela presença de uma população com indivíduos de menor porte. Tal situação corrobora as constatações feitas por Orsi et al. (2002) também no baixo rio Tibagi.

Porém cabe ressaltar, que a manutenção de grupos de jovens (recrutamento) no trecho de Congonhas II, pode estar comprometida em futuro próximo. Com a recente introdução da espécie alóctone, Cichla monoculus Bloch \& SCHENEIDER 1801, que é notoriamente conhecida como um predador muito voraz (Agostinho \& Julio Jr. 1996), podendo desencadear, ainda mais efeitos negativos sobre a estrutura da população de A. altiparanae, pois toda a área final do rio Tibagi apresenta poucos trechos com refúgios eficientes contra a predação dessa espécie.

De forma geral, concordarmos com Wellcomme (1995) e PRYZIBILSKY (1996) que discutem que a variação intraespecífica no crescimento dos peixes ao longo de um rio pode estar associada a fatores, como a poluição química das águas, a degradação do ambiente, a baixa disponibilidade de alimento e a pesca predatória, que ocasionariam a diminuição no tamanho e crescimento destas populações de peixes.

Wоoтоn (1998), destaca que diversos habitats que possibilitam uma melhor oferta de refúgios e alimento, favorecem o crescimento dos indivíduos. Tal situação pode ter ocorrido principalmente em Congonhas I e Três Bocas.

A proporção entre os sexos observada para a espécie nos trechos de Três Bocas e Congonhas I não diferiu significativamente da esperada, encontrada na maioria das espécies de peixes, isto é de 1:1 (um macho para uma fêmea). Porém, as situações encontradas nos trechos de Limoeiro (1:2) e Congonhas II (1:3), podem representar um mosaico de situações que diferiram as proporções sexuais. A questão do maior comprimento das fêmeas poderia ser um motivo de prevalência das mesmas (menor predação), ou ainda a mortalidade e a natalidade poderiam estar atuando de modo diferencial, bem como a pressão de fatores abióticos.

VAzzoler (1996), sugere que o crescimento pode ser um fator que contribui para as diferenças na distribuição sexual, em função de crescimento diferencial entre machos e fêmeas. Autores como, BARBIERI (1992) e BALTZ et al. (1998), acreditam que as causas deste fato residem na seletividade de aparelhos de captura, na estratificação natural da população e principalmente no crescimento distinto entre os sexos. Atingindo maiores tamanhos, as fêmeas podem explorar seus habitats de forma mais eficaz, pois o risco de predação fica reduzido, nesse

Revista Brasileira de Zoologia 21 (2): 207-218, junho 2004 
sentido, a prevalência destes indivíduos de maior tamanho, em biótopos menos favoráveis como no trecho Limoeiro fica compreendido.

O fator de condição relativo nos possibilitou verificar de modo comparativo e eficaz, a situação da espécie em cada trecho, aliás, corroborando aos demais resultados, em que a composição em tamanho de $A$. altiparanae não segue um padrão único. Tal analise demonstrou, quanto os espécimes do trecho de Congonhas II destacaram-se dos demais, indicando de certa forma que os padrões das condições de "bem estar" da espécie neste trecho foram inferiores aos outros, com os valores médios de Kn sempre abaixo do esperado.

O fator de condição relativo (Kn) apresentou diversas vantagens sobre o fator de condição tradicionalmente utilizado (K), pois existe uma contemplação do crescimento alométrico da espécie e é comparável estatisticamente com um valor centralizador $(1,0)$, independente da espécie, do sexo e do comprimento dos exemplares, não sendo afetado por mudanças sazonais na proporção entre os comprimentos (Benedito-Cecílio \& AgostiNHO 1997).

LiAO et al. (1995) ressaltam que a observação das condições das populações utilizando-se do fator de condição relativo possibilita estabelecer relações com diversos fatores (abióticos e bióticos) que podem interferir no crescimento das espécies. Nesse sentido, as condições ambientais pregressas e a estrutura da assembléia de peixes do trecho Congonhas II (porção com características de reservatório), podem realmente ter interferido na estruturação populacional da espécie. Corroboram a esses resultados a observação de ORsi et al. (2002) para a assembléia de peixes do baixo rio Tibagi, onde a diminuição no comprimento e no crescimento foi constatada devido a pressão de fatores ambientais.

Os padrões de distribuição da espécie Astyanax altiparanae indicaram que a mesma utiliza, de modo característico e próprio o recurso espaço, apresentando dois padrões. Um preferencialmente, junto à superfície na coluna de água e próximo às margens na região litorânea, preferencialmente nos ambientes de maiores tamanhos, como o trecho de Limoeiro e Congonhas II, e outro nos trechos de Três Bocas e principalmente em Congonhas I, em que a espécie utilizou amplamente os espaços, logicamente de forma mais eficaz, por serem ambientes de menor proporção espacial.

Este fato pode ser caracterizado como uma tática eficaz na exploração destes ambientes e assim diminuir a competição interespecífica e intraespecífica, seja por alimento ou por espaço. Apesar de não ter sido incluído nesse estudo um enfoque ecomorfológico, pode-se sugerir que características como a forma do corpo, que possibilita ótima hidrodinâmica e a boca terminal, que amplia a área de captura de alimento, como estruturas capazes de facilitar tal comportamento (WINEMILLER et al. 1995).

As diferenças encontradas na distribuição espacial da espécie tiveram fortes indícios de serem decorrentes das características abióticas de cada trecho, e também a acuidade visual, pareceu constituir uma importante característica de Astyanax altiparanae, que em ambientes com maior transparência, caso de Congonhas I, conseguiu ocupar vários micro habitats no trecho. Corroborando a isso Mathews et al. (1992), observaram também que a distribuição espacial dos peixes foi diretamente afetada pela qualidade da água.

Esteves \& Galetti Jr. (1995), Castro \& Cassatti (1997) e Bennemann et al. (2000) sugerem que esses agrupamentos diferenciais de peixes estão relacionados também, a utilização do recurso espaço e são responsáveis pela partilha entre as espécies, sendo que seu uso está associado ao tipo de alimento consumido e o local onde está mais disponível. Outros fatores devem ter influenciado a estratégia de vida da espécie, que agem em conjunto (Lessells 1991), como padrões de comportamento e a reprodução.

Conforme preconizado por Ríncón (1999), estudos visando o conhecimento da utilização de micro-habitats por peixes, ainda estão apenas começando no Brasil. Contudo, a complexidade deste tipo de estudo é grande, pois existe a enorme diversidade de espécies em nossos sistemas de águas interiores e serve como um fator limitante. A nossa abordagem no presente estudo teve como intuito, apenas caracterizar o espaço físico que a espécie poderia ocupar nos trechos, sem a pretensão de esgotar o assunto em pauta.

Ríncón (1999) discute, que ainda não existe um protocolo eficiente que defina as técnicas eficazes que permitam estabelecer qual e como o recurso espaço pode ser utilizado por espécies de peixes. Uma observação continua e sistemática deve ser aplicado a espécie, de forma a abranger mais áreas em que está distribuída, ampliando assim, o conhecimento da historia de vida desse peixe, tão importante ao ecossistema da bacia do alto rio Paraná, como já salientado por VeREgUe \& ORSI (2003).

Podemos então concluir, que apesar de possuir uma grande flexibilidade em ocupar ambientes diferenciados e possuir estratégias para isso, aquele ambiente com melhores condições, caso de Congonhas I, com área mais preservada, próximo da situação original do ambiente, a espécie conseguiu explorar de forma mais eficiente e abrangente, com reflexos positivos concretos na sua estrutura populacional.

Ressaltando dessa maneira, a grande capacidade de ajuste da espécie a situações ambientais diferenciadas, porém com certos limites a questões físicas desses ambientes. Mas dentro desse contexto, A. altiparanae pode apresentar-se como uma das espécies importantes da bacia hidrográfica do rio Paranapanema, como uma espécie de amplo espectro de interação nas assembléias de peixe, devido principalmente a sua estrutura e densidade populacional na comunidade.

\section{AGRADECIMENTOS}

Ao Dr. Oscar Akio Shibatta pelas identificações e colocações, ao Dr. Valdener Garutti, pelas sugestões, a Horácio Mori pela realização das ilustrações, ao Técnico Edson Santana da 
Silva, na qual sua ajuda foi fundamental na viabilização do trabalho e ao curso de pós-graduação da UNESP, Botucatu e UEL pelo apoio logístico.

\section{REFERÊNCIAS BIBLIOGRÁFICAS}

Agostinho, A.A. \& H.F. Julıo Jr. 1996. Ameaça ecológica: peixes de outras águas. Ciência Hoje, São Paulo, 21: 36-44. . 1999. Peixes da bacia do alto rio Paraná, p. 374-399. In: R.H. Lowe - McConNell (Ed.). Estudos ecológicos de comunidades de peixes tropicais. São Paulo, EDUSP, 434p.

Agostinho, A.A.; H.F.Julio JR.; L.C. Gomes; L.M. Bini \& C.S. AgosTINHO. 1997. Composição, abundância e distribuição espaço-temporal da ictiofauna, p.179-208. In: A. E.M. VAzzolER; A.A. Agostinho \& N.S. Hahn (Eds). A planície de inundação do alto rio Paraná: aspectos, físicos, biológicos e socioeconômicos. Maringá, EDUEM, I+460p.

Araujo, F.G. 1998. Adaptação do índice de integridade biótica usando a comunidade de peixes para o rio Paraíba do Sul. Revista Brasileira de Biologia, São Carlos, 58 (4): 547-558.

Baltz, D.M.; J.W. Fleeger; C.F. Rakocinski \& J.N. McCall. 1998. Food, density, and microhabitat: factors affecting growth and recruitment potencial of juvenile salt marsh fishes. Environmental Biology of fishes, Dordrecht, 53: 89-103.

BARBIERI, G. 1992. Biologia de Astyanax scabripinnis paranae (Characiformes, Characidade) do ribeirão do Fazzari. São Carlos. Estado de São Paulo. II. Aspectos quantitativos da reprodução. Revista Brasileira de Biologia, São Carlos, 52: 589-596.

Begon, M.; J.L. Harper \& C.R. Towsend. 1988. Ecología: Individuos, poblaciones y comunidades. Barcelona, Ed. Omega, I+886p.

Benedito-Cecilio, E. \& A.A. Agostinho. 1997. Estrutura das populações de peixes do reservatório de segredo, p. 113-139. In: A.A. Agostinho \& L.C. Gomes (Eds). Reservatório de segredo: bases ecológicas para o manejo. Maringá, EDUEM, $\mathrm{I}+387 \mathrm{p}$.

Bennemann, S.T.; O.A. Shibatta \& J.C. Garavello. 2000. Peixes do rio Tibagi: Uma abordagem ecológica. Londrina. EDUEL, I+64p.

Bennemann, S.T.; A.T. Silva e Souza \& G.R.A. Rocha. 1995. Composición ictiofaunistica en cinco localidades de la cuenca del Rio Tibagi, PR - Brasil. Interciencia, Caracas 20 (1): 7-13.

Bennemann, S.T. \& O.A. Shibatta. 2002. Dinâmica de uma assembléia de peixes do rio Tibagi, p. 433-442. In: M.E. MEDRI; E. Bianchini; O.A. Shibatta \& J. A. Pimenta (Eds). A Bacia do rio Tibagi. Londrina, UEL, I+595p.

Bisson, P.A.; K. Sullivan \& J.L. Nielsen. 1988. Channel hydraulics, habitat use and body form of juvenile coho salmon, steelhead and cutthroat trout in streams. Transactions of the American Fisheries Society, New York, 117: 262-273.

Carvalho, E.D. \& V.F.B. DA Silva. 1999. Aspectos ecológicos da ictiofauna e da produção pesqueira do reservatório de
Jurumirim (Alto do rio Paranapanema, São Paulo), p. 95109. In: R. HENRY (Ed.). Ecologia de Reservatório: estrutura, funções e aspectos sociais. São Paulo, FAPESP, I+799p.

Carvalho, E.; V.F.B da.Silva; C.Y. Fujihara; R. Henry \& F. Foresti. 1998. Diversity of fish species in the Paranapanema river Jurumirim reservoir transition region (São Paulo State, Brasil). Italy Journal of Zoology, Roma, 65: 325-330.

Castro, R.M.C. \& L. Casatti. 1997. The fish fauna from a small Forest stream of the upper Paraná river basin, southern Brasil. Ichthyologic Exploration Freshwaters, Berlin, 7 (3): 337-352.

Copp, G.H. 1992. Comparative microhabitat use of Cyprinid larvae and juveniles in a lotic floodplain channel. Environmental Biology of Fish, Dordrecht, 33: 181-193.

Eckmann, R. 1984. Induced reproduction in Brycon cf. erythropterus. Aquaculture, New York, 38: 379-382.

Esteves, K.E. \& P.M. Galetti JR. 1995. Food partitioning among some Characids of a small Brazilian floodplain lake from the Paraná river basin. Environmental Biology of Fish, Dordrecht, 42: 375-389.

FINK, S.V. \& W.L. FInk.1981. Interrelationships of the ostariophysan fishes (Teleostei). Zoological Journal of the Linnean Society, London, 72: 297-353.

GarutTi, V. \& H.A. BRitski. 2000. Descrição de uma espécie nova de Astyanax (Teleostei: Characidae) da bacia do alto rio Paraná e considerações sobre as demais espécies do gênero na bacia. Comunicações do Museu de Ciências e Tecnologia, Série Zoologia, Porto Alegre, 13: 65-88.

GARUTTI, V. 1989. Contribuição ao conhecimento reprodutivo de Astyanax bimaculatus em cursos de água da bacia do rio Paraná. Revista Brasileira de Biologia, São Paulo, 49 (2): 489-495.

GÉrY, J. 1977. Characoids of the world. J. Géry (ed), T. F. H. Publications, New Jersey. I +672 p.

Hahn, N.S.; I.F. Andrian; R. Fugi \& V.L.L. Almeida. 1997. Ecologia Trófica, p. 209-228. In: A.E.A.M. Vazzoler.; A.A. AgostiNHO \& N.S. HAHN. (Eds). A planície de inundação do alto rio Paraná: aspectos físicos, biológicos e socioeconômicos. Maringá, EDUEM, I+460p.

Lessells, C.M. 1991. The evolution of life histories, p. 32-68. In: J.R. Krebs \& N.B. Davies, (Eds). Behavioral Ecology. New York, Blackwell Scientific Publications, II+ 327p.

LiaO, H.; L.C. Pierce \& D.H. WAhl. 1995. Relative weight (Wr) as a field assessment tool: Relationships with growth, prey biomass, and environmental conditions. Transactions of the American Fisheries Society, New York, 124: 387-400.

Lowe - McConnell, R.H. 1999. Estudos Ecológicos de Comunidades de Peixes tropicais. São Paulo, EDUSP, I+534p.

Mann, R.H.K.; C.A. Mills \& D.T. CrisP. 1990. Geographical variation in the Life-history Tactics of some species of freshwater fish, p. 171-185. In: G.W. Роттs \& R.J. WоотоN (Eds). Fish reproduction: Strategies and Tactics. London, Academic Press, I+371p.

Revista Brasileira de Zoologia 21 (2): 207-218, junho 2004 
Mathews, W.J. 1998. Patterns in freshwaters fish ecology. New York, Chapman \& Hall, I+756p.

Mathews, W.J.; J.D. Hough \& H.W. Robinson. 1992. Similarities in fish distribution and water quality patterns in stream of Arkansas: Congruence of multivariate analyses. CopeIA, Lawrence, (2): 296-305.

Nikolsky, G.V. 1969. Theory of fish population dynamics. Edinburgh, Oliver \& Boyd, I+323p.

Odum, E.P. 1988. Ecologia. Rio de Janeiro, Ed.Guanabara Koogan, II+434p.

Orsi, M.L.; O.A. Shibatta \& A.T. Silva-Souza. 2002. Caracterização biológica de populações de peixes do rio Tibagi, localidade de Sertanópolis, p. 425-432. In: M.E. MEdRI; E.BIANCHINI; O.A. Shibatta \& J.A. Pimenta (Eds). A bacia do rio Tibagi. Londrina, UEL, I+595p.

Paller, M.H.; M.J.M. Reichert \& J.M. Dean. 1996. Use of fish communities to Asses environmental impacts in South Carolina coastal plain streams. Transactions American Fisheries Society. New York, 125 (5): 633-644.

PryzibILSKY, M. 1996. Variation in fish growth characteristics along a river course. Hydrobiologia, Dordrecht, 325: 3946.

RickLEFs, R.E. 2003. Economia da Natureza. Rio de Janeiro, Guanabara Koogan, V+469p

Ríncòn, P.A. 1999. Uso do micro-habitat em peixes de riachos: métodos e perspectivas, p. 23-90. In: E.P. CARAmaschi; R. MAZZONi \& P.R. PERES-Neto (Eds). Ecologia de peixes de riachos. Rio de Janeiro, PPGE-UFRJ, Série Oecologia Brasilienses, vol. VI, XVI+260p.

SABINO, J. 1999. Comportamento de peixes em riachos: métodos de estudo para uma abordagem naturalística, p. 183208. In: E.P. Caramaschi; R. Mazzoni \& P.R. Peres-Neto (Eds). Ecologia de peixes de riachos. Rio de Janeiro, PPGE-UFRJ, Série Oecologia Brasilienses, vol. VI, XVI+260p.

SANTOS, E.P. Dos. 1978. Dinâmica de populações aplicada à pesca e piscicultura. São Paulo, Hucitec, EDUSP, I+129p.

Shibatta, O.A.; M.L. Orsi; S.T. Bennemann \& A.T. Silva-Souza. 2002.
Diversidade e distribuição de peixes na bacia do rio Tibagi, p. 403-423. In: M.E. Medri; E. Bianchini; O.A. Shibatta \& J.A. Pimenta (Eds). A bacia do rio Tibagi. Londrina, UEL, I+595p. SoKAL, R.R. \& F.J. Rohlf. 1981. Biometry. San Francisco, Freeman, II+ 877p.

Southwood, T.R.E. 1988. Tactics, strategies and templates. Oikos, Bonn, 52: 3-18.

VAZzoler, A.E.M. DE M. 1996. Biologia da reprodução de peixes teleósteos: teoria e prática. Maringá, EDUEM. I+169p.

Vazzoler, A.E.A. De M. \& N.A. Menezes. 1992. Síntese de conhecimentos sobre o comportamento reprodutivo dos Characiformes da América do Sul (Teleostei, Ostariophysi). Revista Brasileira de Biologia, São Carlos, 52 (4): 627-640.

Veregue, M.L.A. \& M.L. OrSi. 2003. Biologia reprodutiva de Astyanax scabripinnis paranae (Eigenmann) (Ostheichthyes, Characidade), do ribeirão das Marrecas, bacia do rio Tibagi, Paraná. Revista Brasileira de Zoologia, Curitiba, 20 (1): 97-105.

Welcomme, R.L. 1995. Relationships between fisheries and the integrity of rivers systems. Regulated rivers: research and management, London, (11): 121-136.

Winemiller, K.O. 1989. Patterns of variation in life history among South American fishes in seasonal environmentals. Oecologia, Paris, 81: 225-241.

. 1996. Dynamic diversity: fish communities of tropical rivers, p. 99-134. In: M.L. Cody \& J.A. SMallwood (Eds). Long - term studies of vertebrate communities. Orlando, Academic Press, I+189p.

Winemiller, K.O. \& D.C. TAPHorn. 1989. La evolución de las estrategias de vida en los peces de los Llanos occidental de Venezuela. Biollania, Caracas, 6: 77-122.

Winemiller, K.O.; L.C. Kelso-Winemiller \& A.L.Brenkert. 1995. Ecomorphological diversification and convergence in fluvial cichlid fishes. Environment Biology Fish, Boston, 44: 235-261.

Wоотоn, J.R. 1998. Ecology of teleost fishes. Dordrecht, Kluwer Academic Publishers, II+386p.

Recebido em 08.VII.2003; aceito em 30.IV.2004. 